\title{
ENSINO REMOTO DE CIÊNCIAS: ANÁLISE DAS PERSPECTIVAS DOS PROFESSORES DOS ANOS FINAIS DO ENSINO FUNDAMENTAL DA REDE PÚBLICA DE ENSINO DO MUNICÍPIO DE HIDROLÂNDIA-CE
}

\author{
REMOTE SCIENCE TEACHING: ANALYSIS OF THE PERSPECTIVES OF TEACHERS \\ IN THE FINAL YEARS OF ELEMENTARY EDUCATION IN THE PUBLIC SCHOOL \\ SYSTEM IN THE MUNICIPALITY OF HIDROLÂNDIA-CE
}

\author{
Francielly Rodrigues de Farias ${ }^{1}$
}

Antônia Nádia Brito dos Santos²

\section{Mônica Dias Soares 3}

Filipe Gutierre Carvalho de Lima Bessa ${ }^{4}$

\begin{abstract}
RESUMO: A disseminação do novo coronavírus, associada às medidas de contenção impostas pelas autoridades governamentais em concordância com órgãos sanitários, fizeram com que escolas em todo o mundo suspendessem atividades presenciais e adotassem uma modalidade de ensino emergencial conhecida por ensino remoto. Através do presente trabalho objetiva-se diagnosticar e pontuar as principais dificuldades e perspectivas encontradas pelos professores de Ciências dos anos finais do ensino fundamental da rede pública do município de Hidrolândia-CE. Mediante aplicação de questionário através da plataforma google forms, identificou-se boa aprovação dos professores com a metodologia emergencial, porém os mesmos encontram dificuldades com tecnologias digitais e em contatar os alunos devido fatores socioeconômicos, além de encontrar divergências a respeito do ensino híbrido antes da imunização da população e como aliado permanente no ensino.
\end{abstract}

Palavras-chave: Isolamento social; Ensino remoto; Educação.

\footnotetext{
1 Acadêmica de Ciências Biológicas da Universidade Estadual Vale do Acaraú-UVA, e-mail: r.francielly@live.com.

2 Acadêmica de Ciências Biológicas da Universidade Estadual Vale do Acaraú-UVA, e-mail: nadiabs_@outlook.com.

3 Acadêmica de Ciências Biológicas da Universidade Estadual Vale do Acaraú-UVA, e-mail: msoaresdias219@gmail.com.

${ }^{4}$ Mestre em Bioprospeç̧ão Molecular/Professor do Curso de Ciências Biológicas da Universidade Estadual Vale do Acaraú-UVA, e-mail: filipe_carvalho@uvanet.br
} 
ABSTRACT: The spread of the new coronavirus, coupled with the containment measures imposed by government authorities in agreement with health agencies, caused schools around the world to suspend face-to-face activities and adopt an emergency teaching modality known as remote teaching. This work aims to diagnose and point out the main difficulties and perspectives encountered by science teachers in the final years of elementary school in the public school in the municipality of Hidrolândia-CE. Through the application of a questionnaire through the google forms platform, good approval by teachers was identified with the emergency methodology, but they face difficulties with digital technologies and in contacting students due to socioeconomic factors, in addition to finding disagreements about hybrid education before the population's immunization and as a permanent ally in education.

Keywords: Social isolation; Remote teaching; Education.

\section{INTRODUÇÃO}

Em dezembro de 2019, a cidade chinesa de Wuhan, deparou-se com a epidemia de um novo coronavírus, cientificamente identificado por SARS-COV-2, até então sem origem comprovada e causador de uma doença de caráter respiratório nomeada de COVID19. A rápida disseminação do SARS-COV-2, alarmou entidades governamentais e sanitárias quanto uma possível emergência global, onde no dia 30 de janeiro do ano de 2020 a Organização Mundial da Saúde (OMS) declarou Emergência em Saúde Pública de Importância Internacional (ESPII), posteriormente, aos decorridos II dias do mês de março a doença foi tipificada como pandemia.

Por tratar-se de um vírus propagável facilmente, através de gotículas respiratórias e até então sem protocolo de tratamento comprovadamente eficaz, a OMS decretou medidas de contenção pautadas no isolamento e distanciamento social. A disseminação do novo coronavírus (SARS-COV-2), associada às medidas de contenção impostas pelas autoridades governamentais em concordância com órgãos sanitários, fizeram com que, entre diversas outras medidas de contingência, escolas em todo o mundo suspendessem temporariamente suas atividades presenciais e adotassem uma modalidade de ensino emergencial conhecida por ensino remoto.

No Brasil, o primeiro caso detectado de infecção pelo coronavírus, ocorreu dia 26 de fevereiro na cidade de São Paulo, segundo o Ministério da Saúde. Desde então, com o 
avanço da doença em território nacional, medidas rigorosas de contenção foram impostas, a fim de remediar a situação, entre elas a suspensão das aulas presenciais. Com os casos de COVID-ı9 em ascensão, o governador do estado do Ceará, no exercício de suas atribuições legais, emitiu o decreto $\mathrm{N}^{\circ} 33.510$ de 16 de março de 2020, no que decreta "situação de emergência em saúde e dispõe sobre medidas para o enfrentamento e contenção da infecção humana pelo novo coronavírus." (CEARÁ, 2020), onde em seu artigo $3^{\circ}$, parágrafo III, suspende:

Atividades educacionais presenciais em todas as escolas, faculdades e universidades, das redes de ensino pública, obrigatoriamente a partir de 19 de março, podendo essa suspensão iniciar-se a partir de I7 de março.

Com as escolas temporariamente fechadas e as aulas presenciais suspensas, conselhos municipais e estaduais de Educação aguardavam pareceres dos órgãos educacionais superiores. Em 17 de março de 2020 o Ministério da Educação (MEC) emitiu a portaria $\mathrm{N}^{\circ} 343$ na qual: "Dispõe sobre a substituição das aulas presenciais por aulas em meios digitais enquanto durar a situação de pandemia do Novo Coronavírus-COVID-i9."(BRASIL,2020).

A implementação do ensino remoto modificou a estrutura de ensino vigente há tantos anos na educação básica. Professores precisaram adaptar-se ao método emergencial de ensino e de aprendizagem baseado no uso de tecnologias digitais da informação e comunicação (TDIC's), adaptando seus planejamentos, gerindo seu tempo, buscando práticas inovadoras e novas formas de abordagem.

Neste processo, muitos educadores adaptaram suas aulas para recursos que pudessem ser utilizados em meios digitais e neste aspecto melhor se familiarizarem com a tecnologia para conseguir dar aulas a distância através do ensino remoto. (CORDEIRO, 2020, p. 3).

Nesta perspectiva, tratar de uma formação que vise a construção dinâmica da aprendizagem por competências levando em consideração a capacidade de uso crítico das diversas linguagens e tecnologias digitais, elementos presentes na Base Nacional Comum Curricular (BNCC), tem sido um constante alvo de debate e considerações a partir do atual cenário, sendo este um ponto crítico na formação inicial e continuada de professores.

O trabalho configura-se num importante instrumento de análise diante do atual cenário pandêmico que estamos vivenciando associado às medidas de contenção baseadas no distanciamento e isolamento social, que modificaram a metodologia de ensino e de aprendizagem da educação básica. Desta forma trabalhos que buscam diagnosticar perspectivas acerca da metodologia de ensino e de aprendizagem emergencial implementada, tornam-se de grande valia para as entidades governamentais e educacionais, comunidades escolares e para a sociedade como um todo. 
Espera-se que as reflexões propostas por esta pesquisa, possam contribuir com a comunidade escolar, licenciando e entidades educacionais do município de Hidrolândia-CE. Além de propor no território nacional e internacional elementos de investigação que discutam os impactos educacionais promovidos pela pandemia, através da percepção docente.

Objetiva-se então, diagnosticar e pontuar as principais perspectivas e dificuldades encontradas pelos professores de Ciências dos anos finais do ensino fundamental da rede pública do município de Hidrolândia-CE, através da implementação de práticas no ensino remoto.

\section{Percurso metodológico}

A pesquisa caracteriza-se como sendo básica, de natureza quanti/qualitativa com abordagem exploratória, optando-se por investigação através de estudo de caso e análise textual discursiva (ATD).

Para a realização do presente trabalho, foi realizado previamente, levantamento bibliográfico através de descritores específicos para a temática, tais como: pandemia, ensino remoto, TDIC's, educação, e ensino híbrido. A obtenção de dados realizou-se mediante elaboração de questionário on-line (apêndice I) por meio da ferramenta Google Forms, composto por perguntas objetivas e abertas e aplicado a 12 professores de ciências dos anos finais do ensino fundamental da rede pública de ensino do município de Hidrolândia-CE, totalizando I0o\% de população amostral. Os participantes foram informados previamente do teor e objetivo da pesquisa, firmando acordância de ciência livre e esclarecido, atendendo aos princípios éticos da pesquisa.

Os dados quantitativos foram apresentados no decorrer das discussões em percentuais. Os dados qualitativos de análise de discurso, através das respostas mais representativas de acordo com os questionamentos apontados, foram analisados e discutidos mediante embasamento teórico específico, através de artigos, livros, revistas e demais produções de cunho acadêmico e informacional de relevância sobre a temática.

\section{Resultados e discussão}

Sendo a pesquisa de caráter básico, através de estudo de caso e análise de discurso, apresentando dados quanti/qualitativos obtidos através de questionário estruturado através da ferramenta Google forms e aplicado com 12 professores de Ciências do município de Hidrolândia-CE, totalizando I0o\% de população amostral, buscou-se respostas para a seguinte problemática: "Quais as principais dificuldades e desafios enfrentados no exercício remoto do professor de ciências diante a pandemia da COVID-ı??”. 
A presente discussão buscou diagnosticar e pontuar as principais perspectivas dos professores de Ciências das escolas públicas do município de Hidrolândia-CE frente ao ensino remoto implementado por efeito da pandemia. A partir da análise dos resultados, quando perguntados sobre o grau de satisfação a respeito das atividades remotas, $62,5 \%$ dos professores responderam que acham a metodologia "boa", diante a situação que estamos vivenciando, os que caracterizaram como regular correspondem à 37,5\%. Com relação a participação qualitativa dos alunos nas aulas, $75 \%$ julgaram ser regular e $25 \%$ acreditam que seja uma boa participação. Sobre os pontos supracitados, algumas variáveis foram analisadas com a finalidade de entender e discutir as repostas gerais que os professores atribuíram à metodologia emergencial.

Ao serem questionados sobre suas principais dificuldades, relataram:

$$
\begin{aligned}
& \text { Resposta I } \\
& \text { "Dominar as plataformas" } \\
& \text { Resposta } 2 \\
& \text { “Não ter muito conhecimento tecnológico." } \\
& \text { Resposta } 3 \\
& \text { "O uso da tecnologia tenho que aprender a cada dia." }
\end{aligned}
$$

As respostas supracitadas, interligam-se com outra dado relevante, as habilidades dos professores com TDICs, os que julgam possuir baixa habilidade, correspondem à $25 \%$, seguido de $58 \%$ que consideram possuir habilidade mediana e $17 \%$ julgam possuir alta competência com as tecnologias digitais.

Vivemos a era da informação e comunicação, diante uma sociedade tecnológica e globalizada a integração das tecnologias digitais na educação ganham destaque, bem como a formação dos professores para a utilização destas de forma integrada nos meios educacionais (RODRIGUES, 2014). Para que tal integração e utilização das TDIC's ocorra, exige-se o desenvolvimento de competências digitais por parte dos professores da educação básica, através da formação inicial e continuada (JÚNIOR, 20I8), uma vez que o processo de mudança do ensino e da aprendizagem inicia-se com os professores.

Além de relatarem baixa habilidade com a tecnologia digital, pontuaram dificuldade em contatar os alunos:

\section{Resposta I}

"A dificuldade maior é a baixa qualidade do acesso dos meninos por conta dos dispositivos com pouca memória, bateria ruim etc. Isso acaba fazendo com nem todos participem da aula até o final. Isso sem contar com o problema de alguns alunos compartilharem do mesmo dispositivo com mais um ou dois irmãos de anos letivos diferentes." 


\section{Resposta 2}

"Nem todos participarem por motivos de não terem internet, telefone, etc. Isso o que os alunos dizem."

De acordo com o último censo do IBGE, referente ao ano de 2018, estimasse que cerca de $16 \%$ dos alunos matriculados nos anos finais do ensino fundamental, não possuíam acesso à internet, seja e3la banda larga, ${ }_{3} \mathrm{G}$ ou ${ }_{4} \mathrm{G}$, sendo em grande maioria, estudantes da rede pública de ensino.

A utilização do Ensino Remoto como metodologia emergencial, torna-se positiva para estudantes que possuem acesso à internet e a equipamentos digitais, uma vez que propicia a continuidade de rotina e do processo de aprendizagem, porém muitos alunos carecem dos mesmos e acabam não tendo acesso aos conteúdos on-line (CORDEIRO, et, al, 2020).

Ainda, segundo, Cordeiro, et al 2020:

Uma educação à distância sem práticas inclusivas e alternativas tende a alimentar as discrepâncias socioeconômicas e culminar em altos índices de reprovação e baixa de desempenho de alunos menos favorecidos economicamente que apresentem dificuldade de acesso às tecnologias necessárias à educação em tempos de pandemia. O desafio, então, consiste não apenas em empreender continuidade educacional através do ensino remoto, mas também operacionalizar isso de forma igualitária.

Ao serem questionados sobre as principais metodologias e ferramentas utilizadas no Ensino

Remoto os professores relataram o uso de Tecnologias Digitais da Informação e Comunicação (TDIC's) como Whatsapp e Youtube, ferramentas do Google, Google Meet e Google Formulário. Além de:

\section{Resposta I}

"Metodologias que são viáveis a clientela, como "carro chefe' o feedback associado a questionários e questionários reflexivos.”

\section{Resposta 2}

"Materiais com base da bncc da nossa região adaptada para o ensino remoto.

A utilização de TDICs na educação é um fator que contribui para o desenvolvimento de uma das competências propostas pela base Nacional Comum Curricular (BNCC) para a educação básica, a mesma propõe:

Compreender, utilizar e criar tecnologias digitais de informação e comunicação de forma crítica, significativa, reflexiva e ética nas diversas práticas sociais (incluindo as escolares) para se comunicar, acessar e disseminar informações, produzir conhecimentos, resolver problemas e exercer protagonismo e autoria na vida pessoal e coletiva. (BRASIL,2020). 
Ademais, para que a competência seja realmente adquirida, a utilização das TDIC's precisa ser seguida de metodologias eficazes, a fim de garantir, criticidade e reflexão. Para isso, segundo Sancho e Hernandez (2006, p.18):

Requereria professores convenientemente formados, com grande autonomia e critério profissional. Mas também escolas com bons equipamentos, currículos atualizados, flexíveis e capazes de se ligar às necessidades dos alunos. Além de sistemas de avaliação autênticos que possam mostrar o que os alunos tenham realmente aprendido.

A pandemia alavancou a utilização das TDIC's na educação, por um lado contribuindo para o desenvolvimento da quinta competência geral da BNCC para a educação básica. Porém, diante ao Ensino Emergencial implementado, e o pouco tempo para seu planejamento e formação para os professores, fica uma indagação, "Será que a competência está sendo executada e adquirida de forma eficaz?"

Ao serem indagados sobre suas perspectivas diante uma provável aplicação de ensino híbrido antes da imunização da população, relataram:

\section{Resposta I}

"As escolas não tem espaço para aplicar um distanciamento adequado dentro das salas de aulas, e controlar o distanciamento das crianças dentro da escola será muito difícil, alguns alunos tem que andar em ônibus lotados, muitos fatores que vão contra as regras de combate a pandemia."

\section{Resposta 2}

"As tecnologias digitais podem colaborar com o processo de ensino e aprendizagem, os resultados serão a partir de planos de aula, vídeos e texto. Isso enriquece a prática pedagógica por meio do uso integrado das tecnologias."

Diante da perspectiva da resposta oI, as escolas não possuem infraestrutura apropriada para a implementação de um ensino híbrido seguro antes da imunização da população, seguindo as normas estabelecidas pelos órgãos sanitários. Sabendo disso o Ministério da Educação, publicou o "Guia de implementação de protocolos de retorno das atividades presenciais nas escolas de educação básica”, no qual contém medidas sanitárias a serem implementadas, bem como ações de suporte às escolas, com o objetivo de implementação das normas prioritárias enquanto durar a pandemia.

$\mathrm{Na}$ resposta 2, o ensino hibrido é uma solução viável uma vez que o uso das tecnologias colabora para o ensino e aprendizagem, enriquecendo a prática pedagógica. Segundo Nascimento e Gomes (2019) "Nessa proposta as tecnologias são utilizadas com caráter pedagógico, complementando e enriquecendo o ambiente presencial, oportunizando novas interações e possibilidades para os alunos, [..].” 
Pode-se concluir que os discursos são complementares, uma vez tomado conhecimento da falta de infraestrutura das escolas para o exercício seguro da prática híbrida em cenário pandêmico, como também da importância do uso das tecnologias na educação na atualidade. Logo, outro ponto entra em discussão, nos pós pandemia o ensino híbrido poderia ser aliado permanente na educação? Ao serem questionados sobre suas perspectivas diante a hipótese de aplicação de ensino hibrido permanente, declararam opiniões opostas: os que acreditam que sim, representam $50 \%$ dos professores e os que não entendem como uma realidade futura $38 \%$, seguidos dos que relativizam esta prática ${ }_{12 \%} \%$. Ao observar as justificativas dos seus respectivos posicionamentos, observasse:

\section{Resposta I}

"O ensino híbrido é uma das maiores tendências da educação, que promove uma mistura entre o ensino presencial e online, integrando a educação a tecnologia, que já permeia tantos aspectos de vida do estudante."

\section{Resposta 2}

"O ensino híbrido vem complementar as atividades e práticas pedagógicas, inclusive aquelas inerentes a sala de aula, um complemento do ensino presencial."

\section{Resposta 3}

"Pois nem todos irão participar."

\section{Resposta 4}

"Por que nem todos os alunos tem acesso à internet."

De acordo com a análise textual de discurso dos professores nas respostas i e 2, evidenciamos apreço para com a metodologia híbrida, evidenciando-a como inovadora, integradora e complementar ao presencial. Porém, encontram-se equívocos no que diz respeito ao conceito e função do ensino híbrido, não podendo ser visto como um complemento ao tradicional, mas sim uma forma de ensino que torna o presencial e o virtual indissociáveis. (BRITO, 2020).

Em contraponto, encontra-se o discurso dos professores 3 e 4, que se opõem a metodologia hibrida, devido fatores socioeconômicos já mencionados e discutidos inicialmente.

\section{Considerações finais}

A pandemia provocada pelo novo coronavírus (SARS-COV-2) causou impactos e modificações imensuráveis. Professores de todo o mundo tiveram que encarar uma nova realidade, modificar sua prática pedagógica, potencializar suas habilidades e criatividades, além de desenvolverem competências para o trabalho remoto pautadas na nova forma de comunicação com os alunos por meio do uso das tecnologias digitais da informação e comunicação (TDIC's) na educação. 
A utilização de TDIC's permeia há muitos anos na sociedade, principalmente entre os mais jovens, porém, a sua aplicação e investimento na educação eram escassos. Com a pandemia da COVID-I9, a educação tradicionalista teve que modificar-se, mesmo que emergencialmente. Esperase, portanto, que a Educação siga avançando, na cultura digital, atualizando-se ao mundo contemporâneo, colocando o aluno como protagonista, e, principalmente, valorizando um dos principais colaboradores da mudança da sociedade, o professor.

No município de Hidrolândia-CE, professores de Ciências relataram possuir dificuldades com equipamentos tecnológicos digitais, bem como em contatar alguns alunos, devido fatores socioeconômicos. Pautaram a utilização de TDIC's, como nova forma de mediar aulas, evidenciando, Whatsapp, Youtube e Ferramentas Google como fundamentais para o cenário. Ao falarmos sobre ensino híbrido, antes da imunização da população, houver divergências de opiniões, pois segundo suas perspectivas as escolas públicas não possuem infraestrutura suficiente, para uma implantação segura, porém destacam a metodologia como inovadora e integradora.

Muitas dificuldades foram e são encontradas no ensino remoto, a pandemia forçou educadores em todas as vertentes e áreas de atuação a repensarem e mudarem sua prática pedagógica, a utilizarem novas tecnologias que por muitas eram ignoradas no processo educacional. Busca-se então, constantemente, avaliar os impactos, sejam estes positivos ou negativos, da pandemia na

Educação Básica. A certeza que temos é que o efeito da pandemia na educação, tornou-se um objeto de larga necessidade de profundas reflexões quanto ao processo de ensino e de aprendizagem.

\section{Referências bibliográficas}

BRASIL. Portaria MEC $n^{\circ} 343$, de I7 de marco de 2020. Dispõe sobre a substituição das aulas presenciais por aulas em meios digitais enquanto durar a situação de pandemia do Novo Coronavírus - COVID19. Diário Oficial da União, I8 de março de 2020.

BRASIL. INSTITUTO BRASILEIRO DE GEOGRAFIA E ESTATÍSTICA - IBGE. Microdados da Pesquisa Nacional por Amostra de Domicílios Contínua - Pnad Contínua, edição de 2018, trimestre 4 (questionário suplementar de TIC). Rio de Janeiro: IBGE, 29 abr. 2020c. Disponível em: https://bit.ly/2YH7Frf. Acesso em: 27 de dezembro de 2020

BRASIL. Ministério da Educação, Secretaria de Educação Básica. Base Nacional Comum Curricular (BNCC). Brasília, 2017.

BRASIL. Ministério da Educação. Guia de implementação de protocolos de retorno das atividades presenciais nas escolas de educação básica. Brasília: MEC, 2020. Disponível em:https://www.gov.br/mec/ptbr/assuntos/GuiaderetornodasAtividadesPresenciaisnaEducaoBsi ca.pdf. Acesso em: i4 de janeiro de 202I 
BRITO, J.M.S. A singularidade pedagógica do Ensino Híbrido. Revista EAD em Foco, vol ıo, e948, 2020. Disponível em: https://eademfoco.cecierj.edu.br/index.php/Revista/article/view/948/537 Acesso em: is de janeiro de 2021

CARDOSO, C.A; FERREIRA, V.A; BARBOSA, F.C.G. (Des)igualdade de acesso à educação em tempos de pandemia: uma análise do acesso às tecnologias e das alternativas de ensino remoto. Revista Com Censo, vol 7, $\mathrm{n}$ 3, p. 38-46, 2020. Disponível em: http://www.periodicos.se.df.gov.br/index.php/comcenso/article/view/929/554 Acesso em: 27 de dezembro de 2020

CEARÁ. Decreto $n^{\circ} 33.510$, de 16 de março de 2020. Decreta situação de emergência em saúde e dispõe sobre medidas para o enfrentamento e contenção da infecção humana pelo novo coronavírus. Diário Oficial do Estado, 16 de março de 2020.

CORDEIRO, K. M. D. A. O Impacto da Pandemia na Educação: A Utilização da Tecnologia como Ferramenta de Ensino. Disponível em: http://repositorio.idaam.edu.br/jspui/handle/prefix/II57 Acesso em: 26 de novembro de 2020

DE PAUlA, M.C.; MENEZES, A.L.S.; GUIMARÃES, G.T.D. Análise textual discursiva: possibilidades de imersão. In: GUIMARÃES, G. T. D (Org.). Ressignificando os Labirintos da pesquisa qualitativa: exercícios práticos de análise de discurso. Porto Alegre: EDIPUCRS, 2015. p. $15-38$.

https://books.google.com.br/books?id=5atyCwAAQBAJ\&printsec $=$ frontcover\& $\# v=$ onepage\&q\&f =false Acesso em: 29 de novembro de 2020 .

GOMES, V.T.S; RODRIGUES R.O; GOMES, R.N.S; et al. A Pandemia da Covid-ı9: Repercussões do Ensino Remoto na Formação Médica. Revista Brasileira de Educação Médica, Brasília, vol 44, n 4, 2020. Disponível em: https://www.scielo.br/scielo.php?pid=Soroo$55022020000400602 \&$ script=sci_arttext Acesso em: is de novembro de 2020 .

GOVERNO FEDERAL. Coronavírus Brasil, 2020. Casos novos de COVID-i9 por data de notificação. Disponível em: https://covid.saude.gov.br/ Acesso em: 16 de novembro de 2020.

JÚNIOR, A.P.C. Formação Docente e uso de TDICs na Educação Básica. Disponível em: https://cietenped.ufscar.br/submissao/index.php/2018/article/view/29/23 Acesso em: 20 de dezembro de 2020 .

NASCIMENTO, M.C; GOMES, G.R.R. Ensino Híbrido: Um estudo de caso acerca da aplicação da metodologia rotação por estações no Ensino Fundamental. Revista Acta Scientiae et Technicae, vol 7, n I, p. 27-37, 2019. Disponível em: 〈http://uezo.edu.br/ojs/index.php/ast/article/view/254〉. Acesso em: 13 de janeiro de 2021.

RODRIGUES, A.L. Dificuldades, Constrangimentos e Desafios na Integração das Tecnologias Digitais no Processo de Formação de Professores. Atas do III Congresso Internacional das TIC na Educação, p.838-846, 2014. Disponível em: https://repositorio.ul.pt/handle/1045I/34340 Acesso em: I8 de dezembro de 2020

SANCHO, Juana M.; HERNÁNDEZ, Fernando (Orgs.). Tecnologias para transformar a educação. São Paulo: Artmed, 2006 